\title{
SUÁBIOS DO DANÚBIO: “lembrar, escrever, esquecer”
}

\section{STEIN, Marcos Nestor. "O Oitavo Dia": produção de sentidos identitários na Colônia Entre Rios-PR (segunda metade do século XX). Guarapuava: \\ UNICENTRO, 2011.}

\section{Marilda Marques*}

“Lembrar, escrever, esquecer” são as palavras com as quais Waldemar Feller, doutor em filosofia e um dos "[...] trezentos e poucos dos denominados pioneiros, ainda vivos, da Colônia Entre Rios ${ }^{1}$ [...],” (STEIN, 2011, p.15) termina o prefácio do livro de Marcos Nestor Stein. Feller apresenta suas memórias sobre a trajetória vivida por ele e seus familiares ao final da Segunda Guerra Mundial, desde Zemlin, Iugoslávia, passando pelos campos de refugiados, situados na Áustria, até chegar ao Brasil. É possível perceber, em sua narrativa, um questionamento acerca da identidade desse grupo de refugiados - os Suábios do Danúbio.

Marcos Nestor Stein ${ }^{2}$, partindo de sua trajetória de pesquisa acerca da identidade étnica alemã, escolheu, para sua tese de doutorado ${ }^{3}$, refletir sobre a identidade do grupo suábios do Danúbio. Nas palavras do autor, a obra tem como tema principal:

[...] perceber como a identificação "suábios do Danúbio" é elaborada, imaginada e, por meio de quais marcos cristalizados nos discursos sobre a

\footnotetext{
* Mestranda do Programa de Pós-Graduação em História, com área de concentração em História, Poder e práticas Sociais da Universidade Estadual do Oeste do Paraná - UNIOESTE. Orientador Marcos Nestor Stein. Email: marilda-marques@uol.com.br.

${ }^{1}$ A Colônia Entre Rios, localizada no município de Guarapuava, Centro Sul do estado do Paraná.

2 Docente do Curso de História da Universidade Estadual do Oeste do Paraná. Sua trajetória é permeada por questões que circundam a identidade étnica alemã, mais especificamente, o que se produz em nível de discursos sobre eles, tendo em vista que na dissertação de mestrado problematizou os discursos que norteavam a identificação da germanidade do Município de Marechal Candido Rondon no Extremo Oeste do Paraná.

${ }^{3}$ A Obra resenhada é produto da tese de doutorado em História, apresentada ao Departamento de História da Universidade Federal de Santa Catarina- UFSC, no ano de 2008.
} 
história do grupo é fomentado o sentimento de pertencimento, de (re)criação de um "eu" coletivo na colônia Entre Rios".(STEIN, 2011, p.31)

Stein fez uso de fontes escritas e imagéticas. Analisou jornais, livros, relatórios, atas, entrevistas. Pesquisou os arquivos do Museu (Heimatmuseum) da colônia de Entre Rios, da Biblioteca Pública do Paraná, Instituto Martius-Staden (SP) e órgãos de preservação da memória suábia, também na Alemanha ${ }^{4}$.

$\mathrm{Na}$ introdução, o autor apresenta, de forma detalhada, o referencial teórico e metodológico que fundamenta sua pesquisa. Discute, com precisão, questões como identidade, memória coletiva e sentidos identitários, a partir de autores como Le Goff, Pollak, Hall, Portelli, Rüsen, Todorov.

A obra está disposta em quatro capítulos, cada um deles trata de forma articulada as fontes analisadas, quais discursos sobre a identificação dos suábios elas revelam e em que momento foram criadas.

O primeiro capítulo é nomeado "Apátridas em busca de uma nova pátria”: deslocamentos, adaptações e encontros. Como o próprio nome sugere, trata-se dos refugiados, procedentes de diversas partes da Europa. Uma parte desses contingentes era composta pelo grupo Suábios do Danúbio, descendentes de alemães, à espera de uma "nova pátria”, mediante ajuda humanitária. A denominação do termo suábios do Danúbio, "Donauschwaben ${ }^{5}$, decorre do desmembramento do Império Austro-Húngaro e as divisões onde povoavam os suábios entre Hungria, Iugoslávia e Romênia, no contexto da pós-Primeira Guerra. Porém, com a chegada da Segunda Guerra Mundial intensificaram-se os conflitos interétnicos. Segundo o autor, “[...] os partisans, apoiados pelo exército russo, acabaram por vencer as tropas alemãs, as quais também eram apoiadas [...], [pelos] suábios do Danúbio”. (STEIN, 2011, p.51). Com a derrota da Alemanha, restou uma multidão de "deslocados de guerra”, dentre eles encontravam-se os suábios do Danúbio.

Segundo Stein (2011), a “Ajuda Suíça à Europa” responsabilizou-se pela execução do projeto da imigração, de parte dos refugiados para o Brasil, mediante contato com governos, somando-se 500 famílias, em torno de 2.500 pessoas, as quais, na sua maioria, eram descritas como “apátridas”. A escolha pelo Paraná, e especificamente Guarapuava, não se deu de forma

\footnotetext{
${ }^{4}$ Bibliothek der Ibero-Amerikanischen Instituts Preubischer Kulturbesits (Berlin- Alemanha), Biblioteca do Instituto Ibero-Americano Preubischer Kulturbesits (Berlim-Alemanha), Casa dos Suábios do Danúbio - Haus der Donauschwaben (Sindelfingen-Alemanha), Munich City Library (Munique - Alemanha) e outros.

${ }^{5}$ Segundo Stein (2011) a denominação Suábios do Danúbio “Donauschwaben” sofreu variações ao longo da história e está relacionada a elementos geográficos e humanos. Foi criado em 1922, pelos geógrafos Robert Sieger, austríaco e Hermann Rüdiger, alemão e suábio.
} 
aleatória. Foram realizadas análises minuciosas em torno da topografia do solo, pH, clima, tamanho do terreno e outros.

Os jornais, analisados pelo autor, tiveram papel preponderante na divulgação da chegada dos imigrantes e na formulação da identificação destes, a partir de 1951. As matérias divulgadas, por um lado, reforçavam aos imigrantes a importância do capital humano que representavam para o Brasil, por outro, tranquilizavam os brasileiros, afirmando que não se tratava de “nazistas”, e sim, pessoas especializadas na triticultura.

Os dois relatórios analisados pelo autor sobre a situação dos primeiros anos da Colônia revelam questões importantíssimas. O primeiro, intitulado Bericht über die Siedlungs-Aktion Brasilien (Relatório sobre a Ação da Colônia no Brasil), pautou a avaliação sobre questões geográficas, climáticas e econômicas. Porém, “os colonos” não foram mencionados neste. O segundo relatório, elaborado em 1951, por Walter Gossner à “Ajuda Suíça à Europa”, trouxe à tona a realidade e os problemas vividos no dia a dia da Colônia.

O segundo capítulo é nomeado “Aculturação e Identidade Étnica”. Stein pontua, a partir dos discursos do Governador Bento Munhoz da Rocha Neto, na ocasião das comemorações centenárias de emancipação política do Estado do Paraná, a necessidade de consolidar a identidade do povo paranaense, tendo em vista que, para o governador, o Estado ainda não a possuía. A ocupação do território exigia, além de alemães, agricultores ou operários que tivessem uma predisposição para a "aculturação".

Neste cenário comemorativo de 1953, os imigrantes germânicos publicaram um “Memorial Histórico", o qual resultou na publicação do livro “O Paraná e os Alemães”. Um fragmento da obra é dedicado aos suábios do Danúbio. Nele, o autor identifica um "discurso exemplificador" sobre o grupo, onde reforça sua imagem, sua importância no desenvolvimento do Estado e o esforço em “aculturar-se”, ao aprender a língua portuguesa. A Colônia Entre Rios é colocada como um exemplo a ser seguido pelos suábios.

Outro “discurso exemplificador” aparece na peça de teatro intitulada “O Oitavo Dia Der Morgen des Achten Tages”, publicada por Helmut Abeck, ${ }^{6}$ em 1964. A peça, baseada em fatos históricos ocorridos nos dez primeiros anos da Colônia, apresenta uma fonte riquíssima de elementos, falas, posturas, sobre como interpretar a “aculturação” pelos suábios. Ao contrário da fala do Governador, a peça revela as dificuldades dos suábios em aceitar “o outro”, em “aculturar-se”, tendo em vista as denominações atribuídas a este “outro”, os

\footnotetext{
${ }^{6}$ Filho de imigrantes alemães, oriundos da Namíbia, África, Abeck nasceu em 24 de junho de 1916, em Itajaí, Santa Catarina. Graduou-se em Química pela Universidade Federal do Paraná. Publicou vários textos acerca da presença alemã no Paraná. (STEIN, 2011, p.118)
} 
brasileiros aqui estabelecidos: o caboclo, o inferior, o nativo, o preguiçoso o não autônomo, pois necessitava dos suábios, de sua sabedoria e conhecimento, para transformar aquela paisagem que estava ainda “adormecida” em um imenso celeiro agrícola.

Dentro da mesma linha de análise, o autor apresenta reflexões sobre o relatório de Arpad Szilvassy ${ }^{7}$, intitulado Aspectos Gerais da Colonização Comunitária Europeia no Paraná. Nele, mostra que os suábios não se adaptaram ao ambiente como se esperava e propagavam os jornais, tampouco com as pessoas com as quais passaram a conviver: os brasileiros. Diferente da peça de teatro e do próprio discurso do Governo, onde a "aculturação proporcionaria benefícios para ambos, houve o inverso, o medo da mistura étnica”. Ou, como sabiamente apontou o autor, “é o acaboclar, a versão negativa do aculturamento”. (STEIN, 2011, p.155).

No terceiro capítulo, nomeado "Memória de Júbilo: elaboração de sentidos identitários em publicações comemorativas (1971 e 1976), o autor analisa duas produções, as quais visavam à construção identitária coletiva dos suábios. Em 1971, no vigésimo aniversário de Entre Rios, foi publicação o livro de Albert Elfes “Suábios no Paraná” e em 1976, nos 25 anos, o livro Entre Rios: documentário ilustrado da colonização suábio danubiana. A primeira traz mensagens de "pessoas importantes” congratulando a colônia pelo seu aniversário, seguidas de fotografias, acompanhadas de texto explicativo, reforçando a identificação suábia. A segunda é composta por fotografias que retratam a trajetória percorrida pelos antepassados desde a Europa até a chegada ao Brasil. Diante disso, o autor chama atenção quanto às duas obras, tendo em vista que se tratam de narrativas que visam construir uma identificação coletiva dos suábios.

No último capítulo, nomeado "Guardiões da Memória-Identidade” o autor analisa um lugar de memória, o Museu Histórico de Entre Rios - Heimatmuseum, criado em 1971, onde as mulheres, as "guardiãs da memória”, tiveram papel preponderante na montagem do Museu e na coleta dos materiais trazidos e conservados pelos suábios da Alemanha, com significações para o grupo. $\mathrm{O}$ autor, por imagens cuidadosamente selecionadas do interior do Museu, leva o leitor a uma viagem ao passado do grupo e a maneira que fragmentos desse passado são interpretados e preservados por eles, ainda hoje.

Outra fonte de análise são matérias do Jornal de Entre Rios, especialmente a série de entrevista intitulada “Um Povo Luta Pelo Seu Futuro” (Ein Volk Kämpft Um Seine Zukunft),

\footnotetext{
${ }^{7}$ Nascido na Hungria, em 1912, Szilvassy trabalhou em New York, Estados Unidos, como professor visitante da Fundação Kossutho. Em 1963, veio ao Brasil na qualidade de professor na Fundação Escola de Sociologia e Política de São Paulo. (STEIN, 2011, p.148)
} 
publicada em 1994. Com relação à série, o autor apresenta o objetivo de sua publicação, a homogeneização de um discurso sobre a identificação suábia, tendo em vista que os relatos usados foram previamente escolhidos, recortados e as falas empregadas foram interpretadas de forma conclusiva. A história individual torna-se coletiva e os membros se identificam com este coletivo.

O autor, no decorrer da Obra, revela a habilidade de análise das fontes e a articulação destas, permeando toda a problemática não perdendo o foco da pesquisa, e, ainda, permite ao leitor, seus próprios posicionamentos e indagações.

De modo conclusivo, a leitura da Obra instiga novos olhares sobre a produção de sentidos identitários sobre os mais diversos grupos de imigrantes e migrantes presentes dentro e fora do País, prática que se faz urgente e necessária. 